durum Desf) к ржавчинным болезням. // Автореферат .... канд. с.-х. наук. - Алмалыбак: Казахский НИИ земледелия и растениеводства, 2009. - 26 с.

6. Гультяева, Е.И. Структура популяций Puccinia triticina Erikss. на мягкой и твердой пшенице / Е.И. Гультяева, А.К. Ахметова, Е.Л. Шайдаюк, М.К. Аристова // Земледелие и селекция сельскохозяйственных растений на современном этапе. Сборник докладов международной научно-практической конференции, посвященной 60-летию НПЦ зернового хозяйства им. А.И. Бараева, 2016 - С. 309-313.

7. Михайлова Л.А. Методы исследований структуры популяции возбудителя бурой ржавчины пшеницы / Л.А. Михайлова, Е.И. Гультяева, Н.В. Мироненко // Сборник методических рекомендаций по защите растений. - Санкт-Петербург: ВИЗР, 1998. - C. 105-126.

8. Mains, E.B. Physiologic specialization in the leaf rust of wheat; Puccinia triticina Erikss. / E.B. Mains, H.S. Jackson // Phytopathol. - 1926. - V.16. - P. 89-120.

9. Long, D.L. A North American system of nomenclature for Puccinia recondita f. sp. tritici / D.L. Long, J.A. Kolmer // Phytopathology. - 1989. - V. 79(5). - P. 525-529.

10. Гультяева Е.И. Генетическая дифференциация Puccinia triticina Erikss. по микросателлитным локусам на территории России / Е.И. Гультяева, М.К. Аристова, Е.Л. Шайдаюк, Н.В. Мироненко, И.А. Казарцев, А. Ахметова, Е. Косман // Генетика. 2017. №. 9. - C. 1053-1060.

11. Justesen, A.F. The recent history of Puccinia striiformis f. sp. tritici in Denmark as revealed by disease incidence and AFLP markers / A.F. Justesen, C.J. Ridout, M.S. Hovmøller // Plant Pathology. - 2002. - V. 51 (1). - P. 13-23.

12. Szabo, L. S. Development of simple sequence repeat markers for the plant pathogenic rust fungus Puccinia triticina / L.S. Szabo, J.A. Kolmer // Mol.Ecol. Notes. - 2007. - V. 7 (4). - P. 708-710.

13. Duan, $\mathrm{X}$. Isolation of 12 microsatellite loci, using an enrichment protocol, in the phytopathogenic fungus Puccinia triticina / X. Duan, J. Enjalbert, D. Vautrin, C. Solignac, T. Giraud // Mol. Ecol. Notes. - 2013. - V. 3 (1). - P. 65-67.

DOI 10.18699/GPB2020-65

\title{
Оценка цитогенетической стабильности гибридных растений хлопчатника и их беккроссных потомств с замещениями отдельных хромосом
}

Санамьян М.Ф. *, о.б.н., г.н.с. лаб. генетики хлопчатника; Бобохужаев Ш.У., докторант.

Национальный университет Узбекистана, Ташкент, Узбекистан.

*e-mail: sanam_marina@rambler.ru

Изучали мейоз на стадии метафаза I и спорад у гибридных анеуплоидов хлопчатника с замещеенем отдельных хромосом или их плеч. Выявили невысокий уровень нарушений в мейозе. Беккроссирование анеуплоидных гибридов с исходныли линиями привело к снижению мейотического индекса и 
фертильности пыльцы с увеличением числа беккроссов у гибридных анеуплоидных растений в некоторых комбинациях скрещиваний.

Ключевые слова: G. hirsutum, хромосом-замещенные гибриды, циитогенетический анализ.

\section{Evaluation of the cytogenetic stability of hybrid plants of the cotton and their backcross progenies with substitutions of separate chromosomes}

Sanamyan M.F. Doctor of Biological Sciences, chief scientist Cotton Genetics Laboratories, National University of Uzbekistan, Tashkent, Uzbekistan, sanam_marina@rambler.ru

Bobokhujaev Sh.U. PhD student, National University of Uzbekistan, Tashkent, Uzbekistan

We studied meiosis at the metaphase I stage and sporada in hybrid cotton aneuploids with the substitution of individual chromosomes or their arms. It revealed a low level of disturbance in meiosis. Backcrossing aneuploid hybrids with initial lines led to a decrease in the meiotic index and pollen fertility with an increase in the number of backcrosses in hybrid aneuploid plants in some crosses.

Key words: G. hirsutum, chromosome-substitution hybrids, cytogenetic analysis.

Хлопчатник вида $G$. barbadense L. обладает такими свойствами волокна, которые значительно превышают наиболее широко культивируемые сорта вида G. hirsutum L. Попытки перенести гены, ответственные за качество волокна от G. barbadense L. в геном G. hirsutum L. методами обычной межвидовой гибридизации затруднены из-за стерильности и нарушений при расщеплении. Хотя у хлопчатника G. hirsutum L. не получены полные серии анеуплоидных линий, в США проводятся исследования по созданию хромосом-замещенных линий с чужеродными хромосомами. В результате было выяснено, что линии с чужеродными замещениями по хромосомам 2, 6, 16, 18 и отдельным плечам хромосом 5sh, 22Lo и 22sh имели значительное улучшение \% волокна; тогда как линии с замещением по хромосоме 25 - имели сниженный микронейр и увеличенную крепость волокна $[1,2]$.

Материалом для исследований служили моносомные и монотелодисомные линии хлопчатника из Цитогенетической коллекции хлопчатника вида G. hirsutum L. Национального университета Узбекистана [3]. Ранее была проведена унифицированная идентификация унивалентных хромосом у части моносомных линий коллекции с помощью молекулярных SSR-маркеров [4] и тестерных транслокационных линий с идентифицированными хромосомами [5]. Для создания замещенных линий, моносомные 
линии скрещивались с линией Pima 3-79 вида G. barbadense L., затем в гибридных потомствах выделялись межвидовые моносомные гибриды $\mathrm{F}_{1} \mathrm{c}$ замещениями хромосом, которые беккроссировались с исходными моносомными линиями, служившими рекуррентными родителями.

Сравнительный анализ коньюгации хромосом у 29 гибридных моносомиков $F_{1}$ с замещением хромосомы $2,4,6,7$ и 18 , полученных от скрещиваний 14 моносомных линий с линией донором - Pima 3-79 обнаружил нормальную для моносомиков хлопчатника коньюгацию хромосом с формированием 25 бивалентов и одного унивалента разного размера во всех изученных МКП в 12 гибридных семьях, тогда как в одной комбинации скрещивания ( $\mathrm{F}_{1}$ Mo34 х Pima 3-79) один моносомик с замещением хромосомы 6 выделялся присутствием дополнительных унивалентов, а в другой комбинации ( $\mathrm{F}_{1} \mathrm{Mo} 95$ x Pima 3-79) моносомик с замещением по той же хромосоме отличался присутствием одного квадривалента. Четыре гибридных монотелодисомика с замещением отдельных плеч хромосомы 6 и 11, полученные от скрещиваний двух монотелодисомных линий, характеризовались присутствием гетероморфных бивалентов наряду с нормальными закрытыми бивалентами. Анализ стадии спорад микроспор, проведенный у анеуплоидных гибридных растений $\mathrm{F}_{1}$, с замещениями отдельных хромосом или их плеч обнаружил высокий мейотический индекс (от 94,32 $\pm 0,74$ до 99,93 $\pm 0,07$ ) и небольшое число тетрад с микроядрами (от 0,02 $\pm 0,02$ до $1,18 \pm 0,31 \%$ ), что указало на высокую мейотическую стабильность этих гибридных форм. Сравнительный анализ фертильности пыльцы выявил некоторые различия. Так, моносомные гибриды внутри семьи с замещением хромосомы 2 и двух семей с замещением хромосомы 4 имели сходные высокие показатели фертильности пыльцы, тогда как моносомные гибриды внутри других семей с замещением хромосомы 4 ( $\mathrm{F}_{1} \mathrm{Mo} 7 \mathrm{x}$ Pima 3-79, $\mathrm{F}_{1}$ Mo59 х Pima 3-79, $\mathrm{F}_{1}$ Mo60 x Pima 3-79), с замещением хромосомы 6 ( $\mathrm{F}_{1}$ Mo34 x Pima 3-79), а также монотелодисомные гибриды с замещением отдельных плеч хромосомы 6 или 11 ( $\mathrm{F}_{1}$ Telo12 x Pima 3-79 и $\mathrm{F}_{1}$ Тело21 х Pima 3-79) имели различия в фертильности пыльцы, которые были существенными (от 71,34 $\pm 1,28$ у моносомного гибрида $\mathrm{F}_{1} \mathrm{Mo92}$ х Pima 3-79 до 93,12 $\pm 1,35$ \% у моносомного гибрида $\mathrm{F}_{1}$ Mo67xPima 3-79), что также указало на существование специфических различий в фертильности пыльцы у моносомных гибридных растений с замещениями отдельных хромосом.

Сравнительный анализ коньюгации хромосом у 14 гибридных моносомиков $\mathrm{F}_{1} \mathrm{BC}_{1}$ с замещением хромосомы 4, 6, 7 и 18, полученных от беккроссирования четырех моносомных линий, выявил нормальную для моносомиков хлопчатника коньюгацию хромосом с присутствием 25 бивалентов и одного унивалента разного размера. Однако наличие открытых бивалентов у одного моносомного гибрида в варианте $\mathrm{F}_{1} \mathrm{BC}_{1}\left(\mathrm{Mo} 75 \mathrm{x} \mathrm{F}_{1} 104_{2}\right)$, наряду с закрытыми бивалентами, указало на нарушения в коньюгации хромосом. 
Изучение коньюгации хромосом у четырех монотелодисомных гибридов с замещением отдельных плеч хромосомы 6 или 11 обнаружило гетероморфные биваленты, которые подтвердили нехватку одного из плеч этих хромосом. Анализ стадии спорад, проведенный у 13 моносомных растений $\mathrm{F}_{1} \mathrm{BC}_{1}$ с замещением хромосомы 4, 6, 7 и 18 обнаружил высокий мейотический индекс (от $89,89 \pm 1,17$ до $98,99 \pm 0,20)$ и небольшое число тетрад с микроядрами (от $0,05 \pm 0,03$ до $1,34 \pm 0,47 \%$ ). Однако два монотелодисомных гибрида в семье $\mathrm{F}_{1} \mathrm{BC}_{1}$ (Тело21 $\left.\mathrm{x} \quad \mathrm{F}_{1} 100_{1}\right)$ хотя и характеризовались высоким мейотическим индексом (до 92,34 $\pm 1,14$ ), но выделялись увеличением числа

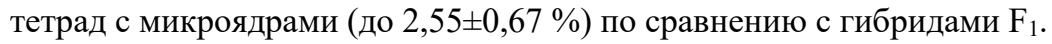

Различия в фертильности пыльцы в различных семьях $\mathrm{F}_{1} \mathrm{BC}_{1}$ были существенными (от 67,27 $\pm 1,45 \%$ у моносомика $\mathrm{F}_{1} \mathrm{BC}_{1}\left(\mathrm{Mo60}\right.$ х $\left.\mathrm{F}_{1} 694_{5}\right)$ до $95,72 \pm 0,91 \%$ у моносомика $\mathrm{F}_{1} \mathrm{BC}_{1}\left(\mathrm{Mo}_{4} \times \mathrm{F}_{1} 529_{16}\right)$ ), что подтвердило существование специфических различий в фертильности пыльцы у гибридных растений с замещением хромосом. Один монотелодисомный гибрид $\mathrm{F}_{1} \mathrm{BC}_{1} \mathrm{c}$ замещением плеча хромосомы 6 характеризовался небольшим снижением фертильности пыльцы (до 85,65 1,37 \%).

Анализ беккроссных потомств $\mathrm{F}_{1} \mathrm{BC}_{2}$, полученных от скрещиваний моносомных и монотелодисомных гибридов $\mathrm{F}_{1} \mathrm{BC}_{1}$ с реккурентными родителями, обнаружил гибридные моносомики $\mathrm{F}_{1} \mathrm{BC}_{2}$ только в 10 гибридных вариантах, поскольку в четырех вариантах моносомные гибриды определить не удалось, из-за сниженной скрещиваемости и небольшого числа гибридных растений в семьях, а также редкого воспроизводства моносомных цитотипов в потомстве. Изучение конъюгации хромосом на стадии метафазаI мейоза у гибридных моносомных форм $\mathrm{F}_{1} \mathrm{BC}_{2}$ с замещением хромосомы 4 , 6, 7 и 18 выявило коньюгацию хромосом с формированием 25 бивалентов и одного унивалента. Анализ стадии спорад микроспор, проведенный у моносомных гибридов $\mathrm{F}_{1} \mathrm{BC}_{2}$, обнаружил высокий мейотический индекс (от $92,27 \pm 0,60$ до $98,04 \pm 0,46$ ) и небольшое число тетрад с микроядрами (от $0,22 \pm 0,15$ до $1,31 \pm 0,41 \%$ ) у большинства изученных растений, за исключением одного гибридного моносомика в варианте $\mathrm{F}_{1} \mathrm{BC}_{2}\left(\mathrm{Mo} 34 \mathrm{x} \mathrm{F}_{1} \mathrm{BC}_{1} 293_{3}\right)$, который выделялся снижением мейотического индекса (до 83,66 $\pm 0,62)$ и существенным увеличением числа тетрад с микроядрами (до 9,23 $\pm 0,77$ \%), причем все другие типы микроспор этого растения также характеризовались присутствием от одного до четырех микроядер, что свидетельствовало о нерегулярности расхождения унивалентов в анафазе мейоза и формировании численно несбалансированных гамет. Анализ фертильности пыльцы, проведенный только в пяти вариантах скрещиваний $\mathrm{F}_{1} \mathrm{BC}_{2}$, обнаружил снижение фертильности пыльцы у растений трех вариантов скрещиваний (до $70,09 \pm 1,57 \%)$.

Сравнительный анализ фертильности пыльцы, проведенный между моносомными гибридами $\mathrm{F}_{1}$ и моносомными беккроссными гибридами 
$\mathrm{F}_{1} \mathrm{BC}_{1}$ и $\mathrm{F}_{1} \mathrm{BC}_{2}$, указал на частичное снижение фертильности пыльцы у гибридных моносомных растений с замещениями отдельных хромосом с увеличением числа беккроссов.

\section{Список литературы}

1. Saha S., J.Wu., J.N. Jenkins, J.C. McCarty, Jr., O.A. Gutierrez, D.M. Stelly, R.G. Percy, and D.A. Raska. Effect of Chromosome Substitutions from Gossypium barbadense L. 3-79 into G. hirsutum L. TM-1 on Agronomic and Fiber Traits // The Journal of Cotton Science. 2004. V. 8. P 162-169.

2. Saha S., Jenkins J. N., WU J., McCarty J. C. and Stelly D. M. Genetic analysis of agronomic and fibre traits using four interspecific chromosome substitution lines in cotton // Plant Breeding. 2008. V. 127. P. 612-618.

3. Sanamyan M.F., Petlyakova J., Rakhmatullina E.M., Sharipova E. World Cotton Germplasm Resources. Chapter 10. "Cytogenetic Collection of Uzbekistan". Intech. - Croatia. - 2014. P. 247- 287.

4. Санамьян М.Ф., Бобохужаев Ш.У., Макамов А.Х., Ачилов С.Г., Абдурахмонов И.Ю. Создание новой серии анеуплоидных линий у хлопчатника (Gossypium hirsutum L.) с идентификацией нехваток отдельных хромосом с помощью транслокационных и SSR-маркеров // Вавиловский журнал генетики и селекции. 2016. - T.20. №5. C.643-652.

5. Санамьян М.Ф., Бобохужаев Ш.У. Идентификация унивалентных хромосом у моносомных линий хлопчатника Gossypium hirsutum L. с помощью цитогенетических маркеров // Вавиловский журнал генетики и селекции. 2019. Т.23. - №7. - С. 836-845.

DOI 10.18699/GPB2020-66

\section{Влияние стимуляторов роста на содержание хлорофилла “a” и "b" и каротиноидов в листьях пшеницы}

Сатторов Б.Н.*, Сафаров Х.Р., Партоев К.

Институт ботаники, физиологии и генетики растений АН Республики Таджикистан, Душанбе

*e-mail: baca6600@mail.ru

В лаборатории генетики и селекции растений Института ботаники, физиологии и генетики растений Академии наук Республики Таджикистан проведены опыты по выявлению действия стимуляторов на содержание хлорофиллов «а», «б» и каротиноидов на ростки четырех сортов пшеницьы. В опьтте изучены ростки сортов пшениць, проросшие в следующих варианmax: 1. Контроль (вода); 2. Водньий раствор стимулятора Узхитан; 3.Водныии раствор ЭРА; 4. Водный раствор Узхитан+ЭРА. Через 10 дней подсчитали количество проросших семян, длины ростков и корней растений по вариантам опыта, а также определили количество хлорофиллов “ $a$ ” $u$ " $b$ " $u$ 